ISSN 1414-6509

\title{
RESTAURANTES POPULARES EM TOLEDO: Um programa de desenvolvimento
}

\author{
Elaine de Oliveira Zanini \\ Professora da Faculdade Assis Gurgacz (FAG/Cascavel-PR). Mestranda em Desenvolvimento Regional e \\ Agronegócio da Universidade Estadual do Oeste do Paraná (UNIOESTE/Campus de Toledo). \\ Endereço para contato: Rua Manaus, 440 Bl 6 apto 403 - Cascavel - PR \\ CEP: 85813-100 - E-mail: elainezanini@gmail.com
}

\section{Mirian Beatriz Schneider}

Professora Doutora da Universidade Estadual do Oeste do Paraná (UNIOESTE/Campus de Toledo). Endereço para contato: Rua Maringá, 3032- Toledo - PR

CEP: 85903-620 - E-mail: mirian-braun@hotmail.com

Recebido em 12 de janeiro de 2016. Aceito em 25 de fevereiro de 2016.

\section{RESUMO}

Este trabalho tem por objetivo principal analisar os restaurantes populares do município de Toledo e sua contribuição para o desenvolvimento regional. O projeto dos restaurantes populares é um grande avanço na construção de uma política de segurança alimentar mais sólida. Por meio do Programa de Aquisição de Alimentos (PAA) do Governo Federal, os restaurantes populares possibilitam acesso à alimentação saudável com baixo custo à população, além de estimular e fortalecer a produção local de alimentos oriundos da agricultura familiar do município. Observou-se que atualmente Toledo possui o maior número de unidades do Estado e é um grande exemplo de sucesso no contexto nacional, servindo de motivação para outros países. Destacam-se neste contexto, as melhorias conquistadas com o projeto, como melhora na qualidade de vida do homem do campo, incentivo ao associativismo e cooperativismo, fortalecimento da feira local, redução dos índices de insegurança alimentar e nutricional queda nos gastos públicos com atendimento nas unidades de saúde, entre outros, evidenciando que essa política pública contribui para o desenvolvimento das regiões onde estão inseridos.

Palavras-chave: Políticas Públicas; Restaurantes Populares; Agricultura Familiar.

\begin{abstract}
This study is meant to examine the popular restaurants in the city of Toledo and its contribution to regional development. The design of the popular restaurants is a major step forward in building a stronger food security policy. Through the Food Acquisition Program (PAA) of the Federal Government, the popular restaurants provide access to healthy food at low cost to the public, and encourage and strengthen the local production of food from the family of the county agriculture. It was observed that Toledo currently has the largest number of state units and is a great example of success at the national level, serving as motivation to other countries. It stands out in this respect the improvements achieved with the project, such as improved quality of life of the peasant, encouraging associations and cooperatives, strengthening the local market, lowering the levels of food insecurity and nutritional decline in public spending on care in health facilities, among others, showing that this public policy contributes to the development of the regions where they live.
\end{abstract}

Key-words: Public Policy; Popular restaurants; Family farming.

Econ. e Desenv., Santa Maria, vol. 27, n.2, p. 243 - 256, jul. - dez. 2015 RE\&D 


\section{INTRODUÇÃO}

À medida que o processo de urbanização avança, maiores são os problemas sociais, e maiores as dificuldades para o combate dos mesmos. Neste sentido, cabe aos países elaborar políticas públicas que possam considerar e compreender essa maior complexidade dos fatos, assegurando assim aos cidadãos seus direitos básicos. Após os anos 80 , tornou-se necessária a formulação de estratégias de desenvolvimento com inclusão social, tentando proporcionar crescimento econômico sem aumentar as desigualdades sociais, dentre essas estratégias encontram-se as políticas públicas.

Para Barros (2007), o Brasil tem necessidade de políticas públicas de combate à pobreza, pois ela está associada à má distribuição dos recursos e não à sua escassez. Neste sentido, Pepe Vargas, ministro do Desenvolvimento Agrário (MDA), informa que no Brasil cresceram os empregos formais e diminuiram as desigualdades, aplicando políticas públicas em conjunto com os governos federal, estadual e municipal. Uma das políticas públicas que está contribuindo para isso são os restaurantes populares, que desde suas primeiras implantações, em 1940, têm contribuído para que a população brasileira tenha uma alimentação saudável com baixo custo. Eles são considerados uma experiência de sucesso, e em conjunto com outras políticas públicas como o Programa de Aquisição de Alimentos (PAA), transforma a realidade da população mais vulnerável, beneficiando as pessoas que vivem no meio rural, fortalecendo a indústria, gerando emprego e dinamizando a economia local (MDA, 2015).

Com o projeto Toledo conseguiu melhorar a qualidade de vida do homem do campo, melhorar o associativismo, fortaleceu a feira local e diminuiu os gastos públicos com atendimento nas unidades de saúde. Em parceira com os produtores familiares de Toledo, o PAA ajuda fortalecer a agricultura familiar na região, essa interação proporciona um produto de qualidade e melhorias na qualidade de vida da população (FUNDAÇÃO DO BANCO DO BRASIL, 2014; SCHIAVINATO, 2015).

Assim, os restaurantes populares deixam de atuar apenas como políticas compensatórias e passam ser progenitores de desenvolvimento das regiões onde estão inseridos, fortalecendo a agricultura familiar, incentivando o cooperativismo e associativismo, diminuindo a fome e a pobreza da população, aumentando o índice de segurança alimentar e nutricional, além de avivar a economia local.

Diante dos apontamentos da literatura vimos que a intervenção do Estado na economia por meio das políticas públicas, se faz necessária para que diminua as desigualdades sociais, promova o desenvolvimento regional e garanta a todos os cidadãos os direitos contidos na constituição brasileira. No próximo capítulo serão apresentados bons exemplos de políticas públicas de sucesso, como políticas de incentivo a agricultura familiar e desenvolvimento regional.

2. Das políticas públicas compensatórias a um programa de desenvolvimento: restaurantes populares em Toledo/PR

As políticas públicas são as respostas organizadas pela sociedade, através do seu sistema político, para atender as necessidades sociais da população (assistência social, saúde, educação, alimentação, habitação, entre outras). Elas visam assegurar direitos de cidadania, promover o desenvolvimento, criando alternativas de emprego e renda como forma compensatória dos ajustes criados por políticas econômicas (MERIGO; ANDRADE, 2010).

Políticas públicas do tipo compensatórias são elaboradas pelos governos federais, estaduais e municipais para diminuir ou solucionar problemas como a fome e a pobreza e as desigualdades

RE\&D Econ. e Desenv., Santa Maria, vol. 27, n.2, p. 243 - 256, jul. - dez. 2015 
sociais, porém, a política compensatória apenas compensa o efeito de algo, atuando sobre o efeito do problema e não sobre a sua causa, sendo necessária a interação com outras políticas públicas para que seu efeito seja multiplicador e transforme a realidade da população mais vulnerável e consequentemente a realidade da região. Um exemplo disso são os restaurantes populares de Toledo que em conjunto com outras políticas públicas conseguiram resultados muito positivos, que vão além de apenas minimizar os problemas sociais. A seguir serão apresentadas as políticas públicas que interagem com os restaurantes populares do município de Toledo, em conjunto elas fortalecem a agricultura familiar local, incentivam o cooperativismo, dinamizam a economia, fornecem alimentação saudável a população mais vulnerável e promovem o desenvolvimento do município.

\subsection{Programa de Aquisição de Alimentos (PAA)}

O Programa de Aquisição de Alimentos (PAA) é uma política pública do Governo Federal criada em 2003 com o objetivo de contribuir com o combate a fome e a pobreza no Brasil e, também, fortalecer a agricultura familiar (MDA, 2015a). Cruz et al (2014, p. 01) define o PAA como "uma política pública de articulação entre produção, comercialização e consumo", onde não se faz necessária licitação.

Os restaurantes populares do município de Toledo fazem uso da política pública PAA, onde adquirem produtos diretamente de agricultores familiares ou de suas organizações do município de Toledo, incentivando os processos de agregação de valor à produção familiar (MDA, 2015). Segundo Cruz (2014), o programa fortalece a produção e a cultura alimentar das populações, avivando a economia local, a formação de estoques estratégicos, melhorando a qualidade dos alimentos advindos da agricultura familiar, ainda incentiva o manejo agroecológico dos sistemas produtivos e a preservação da biodiversidade da região.

Desde sua implantação no ano de 2003 até 2013, os recursos fornecidos ao programa PAA foram cerca de 3 bilhões de reais. No ano de 2013 o programa alcançou o valor de R $\$ 224$ milhões e a previsão de dispêndio para o ano de 2014 é de R 500 milhões (CRUZ, 2014). Conforme o Plano Nacional de Segurança Alimentar e Nutricional (2014), entre os anos de 2003 e 2005, participavam do PAA, em média, 60 mil agricultores familiares por ano. Já entre 2006 e 2011 o programa tinha 150 mil agricultores familiares cadastrados e no ano de 2012 mais de 185 mil agricultores familiares foram beneficiados em todo o Brasil.

\subsection{Compra Direta}

Essa modalidade possibilita a formação de estoques públicos, destinados ao abastecimento social ou a venda, por meio da compra de produtos específicos estipulados pelo Grupo Gestor do PAA, produtos estes que são usados na composição de cestas para distribuição para grupos específicos, assim o programa auxilia na regulação de preços de alimentos, na movimentação de safras e estoques e ainda contribui para a segurança alimentar e nutricional. O limite anual é de $\mathrm{R} \$ 8.000,00$ (oito mil reais) por unidade familiar para fornecer alimentos para o programa, com preços definidos pelo Grupo Gestor do Programa. Todos os alimentos devem seguir aos padrões de qualidade previstos pela legislação vigente, os agricultores devem possuir a Declaração de Aptidão ao Pronaf (DAP) e ainda preferencialmente fazerem parte de cooperativas ou associações, formais ou informais, não sendo impedidos de participarem individualmente. Os estoques são formados por produtos comprados com recursos do MDS e tem a prioridade para doação, sendo vendidos com autorização do Ministério somente em casos especiais. Já os alimentos comprados com recursos do MDA tem a prioridade para

Econ. e Desenv., Santa Maria, vol. 27, n.2, p. 243 - 256, jul. - dez. 2015 RE\&D 
venda, realizada por leilões eletrônicos ou em balcão, com valores definidos pelo Grupo Gestor do Programa, os alimentos são repassados para doação somente em casos de risco de perda de qualidade dos alimentos estocados, impossibilidade de remoção, manutenção ou venda de forma econômica ou de necessidade de atendimento a ações de segurança alimentar e nutricional (MDS, 2015).

\subsection{Apoio à Formação de Estoques pela Agricultura Familiar}

Seu objetivo é proporcionar aos produtores familiares, meios de apoio à comercialização, segurança de preços e agregar valor aos seus produtos. É um apoio financeiro, para formação de estoques de alimentos por organizações ou associações da agricultura familiar, para depois serem vendidos. Essa modalidade fornece recursos com limites anuais para participação por família de até $\mathrm{R}$ \$ 8.000,00 (oito mil reais) por ano. Quando uma organização de produtores familiares percebe a possibilidade de formação de estoque de algum alimento, é redigida e enviada uma proposta de participação à CONAB do Estado. O valor total da Proposta de Participação não pode exceder o valor de R \$ 1,5 milhão por cada organização/ano, os produtos que serão estocados, o prazo para a formação de estoque, os preços praticados e quem são os agricultores familiares beneficiados, são definidos na proposta. Os agricultores familiares devem ter a Declaração de Aptidão ao Pronaf (DAP) para participarem do processo. A organização/associação recebe a produção dos agricultores familiares, os quais venceram a Proposta de Participação, seleciona os alimentos e os conserva em estoque próprio até a entrega para estoques públicos ou venda para o mercado convencional (MDS, 2015). Entre os anos de 2006 e 2012 foram disponibilizados para essa modalidade, cerca de R 260 milhões, valores que atendem aproximadamente 70 mil agricultores familiares (PLANSAN, 2014).

\subsection{Incentivo à Produção e ao Consumo de Leite}

Auxilia no aumento do consumo de leite pelas famílias em situação de insegurança alimentar e nutricional e fortalece a produção. A modalidade é operada na Região Nordeste e nos municípios do Norte de Minas Gerais com repasses do MDS, por meio de convênios. Os estados conveniados contratam laticínios que recepcionam, coletam, pasteurizam, embalam e transportam o leite para os pontos de distribuição, locais pré-definidos onde as famílias beneficiadas retiram o leite (vaca ou de cabra), em torno de um litro por dia (MDS, 2015).

$\mathrm{O}$ agricultor familiar selecionado entrega sua produção diária de leite no laticínio contratado ou o deposita em tanques de resfriamento, de onde será coletado pelo laticínio. Para participar do PAA Leite, o produtor deve possuir Declaração de Aptidão ao Pronaf (DAP), produzir no máximo 150L de leite/dia e ter comprovante de vacinação dos animais. O produtor possui um limite de recebimento pela venda de até $\mathrm{R} \$ 4.000,00$ (quatro mil reais) por semestre. Se o valor não for utilizado totalmente no semestre, não poderá ser compensado no semestre seguinte. O valor pago ao produtor é estabelecido pelo Grupo Gestor e atualizado semestralmente, de acordo com a média dos preços do mercado local. $60 \%$ do valor são repassados ao produtor e $40 \%$ ao laticínio (MDS, 2015).

\subsection{Compra Institucional}

Possibilita a realização de compras institucionais, tendo maior participação dos produtores rurais, propiciando ampliação de mercados, aumento de renda e o acesso à alimentação saudável para a população e o dinamismo da economia regional. A modalidade permite que estados, municípios e órgãos federais da administração direta e indireta façam a compra de produtos dos produtores rurais

RE\&D Econ. e Desenv., Santa Maria, vol. 27, n.2, p. 243 - 256, jul. - dez. 2015 
pelas chamadas públicas, utilizando recursos próprios e sem licitação. Os produtores fornecedores devem possuir a Declaração de Aptidão ao Pronaf (DAP) para participarem da modalidade. Além dos produtores rurais, cooperativas e organizações que possuam DAP Jurídica também podem vender produtos, respeitando sempre o limite por família. Cada família possui um limite anual para venda de até $\mathrm{R} \$ 20.000,00$ (vinte mil reais), por órgão comprador (MDS, 2015).

\subsection{Compra com Doação Simultânea (CDS)}

Modalidade do PAA gerida pela CONAB, ela é executada somente com recursos advindos do MDS. Seu objetivo é atender estabelecimentos locais de suplementação alimentar, incentivar os agricultores familiares da região a produzirem alimentos que atendam às necessidades de complementação alimentar das escolas, creches, abrigos, asilos, hospitais públicos, restaurantes populares, cozinhas comunitárias e bancos de alimentos e outros definidos pelo grupo gestor do PAA (ARAUJO; SILVA et al, 2013).

Os agricultores familiares devem possuir a Declaração de Aptidão ao Pronaf (DAP) e estar organizados em cooperativas ou associações para poderem participar da CDS. Essas organizações enviam uma Proposta de Participação à CONAB, a proposta tem prazo estipulado e mediante sua aprovação, a organização emite uma Cédula de Produto Rural (CPR-Doação) e passa a fornecer alimentos às entidades. Confirmando a entrega dos produtos, a CONAB fornece os recursos para a organização que realiza o pagamento aos produtos até o limite de $\mathrm{R} \$ 8.000,00$ (oito mil reais) por família no ano. Os agricultores individuais possuem um limite anual de venda para o programa de até $\mathrm{R} \$$ 6.500,00 (seis mil e quinhentos reais). Os alimentos são entregues pelos agricultores na Central de Distribuição do município, ali eles são encaminhados para doação. Os produtos adquiridos dos agricultores familiares são doados às entidades da rede socioassistencial, aos equipamentos públicos de segurança alimentar e nutricional (Restaurantes Populares, Cozinhas Comunitárias e Bancos de Alimentos). A CDS permite a aquisição de alimentos in natura, processados e industrializados, além disso o fornecimento de produtos orgânicos possibilita o pagamento de valores diferenciados (até 30\% a mais do que o valor pago para o alimento convencional) (MDS, 2015).

\subsection{Programa Nacional de Fortalecimento da Agricultura Familiar (PRONAF)}

O PRONAF foi criado em 1995 com o objetivo de apoiar financeiramente as atividades agropecuárias ou não, para implantação, ampliação ou modernização da estrutura de produção, beneficiamento, industrialização e de serviços, no campo ou em áreas comunitárias rurais próximas. Ele é destinado para promover a expansão da produção e da produtividade e também para a redução dos custos de produção (BNDES, 2015). De acordo com BNDES podem ser beneficiados com o programa: agricultores e produtores rurais que compõem as unidades familiares de produção rural e possuem a Declaração de Aptidão ao PRONAF (DAP), a DAP é o meio de identificar os beneficiários do programa e suas organizações associativas (DAP Jurídica). São mais de 196 mil os beneficiados com a DAP no Paraná e pelo menos $80 \%$ dos agricultores familiares do Estado fazem uso ou já utilizaram o PRONAF para financiarem suas atividades agropecuárias (EMATER, 2013).

Para o PLANSAN (2014, p. 52) "a garantia de acesso ao crédito é fundamental para a inclusão produtiva das famílias da agricultura familiar". Em 2012, os agricultores familiares do Paraná, contrataram mais de R\$2 milhões de reais em financiamentos. O aumento dos valores aplicados no PRONAF evoluiu de R \$ 2,4 bilhões em 2002/2003 para os R \$ 18 bilhões atuais. O ano 2013 finalizou com recorde no volume de contratação de crédito do PRONAF. Segundo o Ministério

Econ. e Desenv., Santa Maria, vol. 27, n.2, p. 243 - 256, jul. - dez. 2015 RE\&D 
do Desenvolvimento Agrário (MDA), órgão responsável por promover o desenvolvimento do setor, em 2013 o crédito para a agricultura familiar alcançou $\mathrm{R}$ \$ 18,6 bilhões, valor acima da previsão de $\mathrm{R}$ \$ 18 bilhões (PORTAL BRASIL, 2014).

\subsection{Mais Alimentos Produção Primária}

Vinculado ao PRONAF, a modalidade é uma linha de crédito que financia investimentos em infraestrutura produtiva da agricultura familiar, fazem parte desse programa os produtos: açafrão, arroz, cana-de-açúcar, café, centeio, feijão, mandioca, milho, palmácea para produção de palmito, soja, sorgo, trigo, erva-mate, e as atividades: apicultura, aquicultura, avicultura, bovinocultura de corte e de leite, caprinocultura, fruticultura, olericultura, ovinocultura, pesca e suinocultura. São financiados projetos individuais de até $\mathrm{R} \$ 150$ mil e coletivos de até $\mathrm{R} \$ 750$ mil, com juros de $2 \%$ ao ano, até três anos de carência e até dez anos para pagar. O financiamento de estruturas de armazenagem possui um prazo de até quinze anos, com carência de três anos. O financiamento para às atividades de suinocultura, avicultura e fruticultura chega a $\mathrm{R} \$ 300$ mil. Os contratos firmados estão ligados ao Programa de Garantia de Preços da Agricultura Familiar (PGPAF) (MDA, 2015).

\subsection{Programa de Garantia de Preços para a Agricultura Familiar (PGPAF)}

O programa garante aos produtores familiares que possuem o PRONAF Custeio ou o PRONAF Investimento, em caso de baixa de preços dos alimentos no mercado, um desconto no valor do financiamento, sendo esse desconto a diferença entre o preço de mercado e o preço de garantia do produto. Toda vez que o preço médio mensal de mercado apresentar-se abaixo do preço de garantia da safra, será calculado um bônus em percentual equivalente a essa diferença de preços. Este bônus será aplicado pelo banco no saldo devedor dos financiamentos de custeio do Pronaf efetivados para os produtos do PGPAF, garantindo que os agricultores familiares tenham assegurado o custo de produção para o pagamento do financiamento. O limite fixado para o bônus do PGPAF para cada agricultor (a) familiar é de até $\mathrm{R} \$ 3.500,00$ (MDA, 2015).

\subsection{Assistência Técnica e Extensão Rural (ATER)}

É um serviço que consiste em visitas técnicas nas propriedades rurais para identificar as necessidades e potencialidades de cada família, esse processo acontece do início da safra até o produto chegar ao mercado. Em parceria com o MDS, MDA e o Programa de Fomento às Atividades Produtivas Rurais, a ATER irá transferir recursos financeiros de forma direta e prestar serviços de assistência aos agricultores familiares que precisam deste auxílio (MDS, 2015b). De 2011 a 2014, 2.572 famílias de agricultores familiares do Paraná, de 20 municípios, tiveram o acesso aos serviços de ATER.

\subsection{Programa Nacional de Segurança Alimentar e Nutricional}

Por meio da Lei Orgânica de Segurança Alimentar e Nutricional (LOSAN), (Lei n ${ }^{\circ} 11.346$, de 15 de setembro de 2006), foi criado o Sistema Nacional de Segurança Alimentar e Nutricional (SISAN) com os objetivos de formular e implementar política e planos de Segurança Alimentar e Nutricional (SAN), incentivar a integração entre governo e sociedade, além de promover o

RE\&D Econ. e Desenv., Santa Maria, vol. 27, n.2, p. 243 - 256, jul. - dez. 2015 
acompanhamento, monitoramento e a avaliação da Segurança Alimentar e Nutricional no País (PLANSAN, 2011).

No âmbito da segurança alimentar e nutricional, o Brasil tem tido resultados expressivos desde 2003, ano em que foi vinculado ao Programa Fome Zero do Governo Federal. Ao dar prioridade ao combate à fome e à pobreza, foram criadas políticas públicas para a melhoria das condições sociais e de alimentação, o que gerou impactos positivos na segurança alimentar e nutricional no País (PLANSAN, 2011). Os indicadores sociais e nutricionais apresentaram significativa melhora desde 2003, como a redução da pobreza, porém, o País ainda tem significativo percentual de domicílios em condição de insegurança alimentar (CONSEA, 2009). A redução do índice de segurança alimentar grave diminuiu $1,95 \%$, mas ainda há preocupação de eliminar esse percentual do cenário brasileiro. A redução dos índices de pobreza e extrema pobreza no Brasil chegaram a mais de $50 \%$ entre o ano de 2002 e 2012 (PLANSAN, 2014). Em relação aos indicadores sociais, muito há de ser feito para que o Brasil consiga erradicar a fome e a pobreza. Políticas públicas como os Restaurantes Populares fazem parte da rede de equipamentos públicos de segurança alimentar e nutricional (MDS, 2015c).

Em dezembro de 2014 o prefeito Beto Lunitti sancionou a Lei $N^{\circ} 2186 / 2014$, que cria os componentes do município do Sistema Nacional de Segurança Alimentar e Nutricional e estipula parâmetros para elaboração e implementação do Plano Municipal de Segurança Alimentar e Nutricional. O Secretário de Administração, Amauri Linke informa que a medida possibilita ao município receber recursos dos Governos Estadual e Federal. Para o prefeito a alimentação adequada é um direito primordial do ser humano. "Cabe ao poder público adotar as políticas e ações que se façam necessárias para respeitar, proteger, promover e prover o direito humano à alimentação adequada e segurança alimentar e nutricional de toda a população", disse (PREFEITURA MUNICIPAL DE TOLEDO, 2015).

\subsection{Programa Nacional de Alimentação Escolar (PNAE)}

O Programa PNAE popularmente conhecido como merenda escolar, é gerido pelo Fundo Nacional de Desenvolvimento da Educação (FNDE) e foi criado em 1955 para oferecer alimentação escolar e de ações de educação alimentar e nutricional, contribuindo para o crescimento, o desenvolvimento, a aprendizagem, o rendimento escolar dos estudantes e a formação de hábitos alimentares saudáveis. Em 2010 foram atendidos 45,6 milhões de estudantes com um orçamento de R\$ 3 bilhões. Para beneficiar 43 milhões de estudantes da educação básica e de jovens e adultos, o orçamento do programa para 2014 é de $\mathrm{R} \$ 3,5$ bilhões. O Programa apresentou grandes avanços entre os anos 2003 e 2011, como o aumento de $130 \%$ no repasse financeiro per capita, no entanto, o valor repassado pelo Governo Federal ainda é insuficiente, por conta disso, a complementação por parte de estados e municípios é muito importante, infelizmente justamente nas localidades mais pobres, não ocorre qualquer complementação (FNDE, 2015; PLANSAN, 2011; SOARES et al, 2013).

Em julho de 2009, o Governo decretou a Lei N 11.947 , 'Lei da Alimentação Escolar', a Lei obriga os estados, os municípios e o Distrito Federal gastarem um percentual do valor repassado pelo Governo Federal com alimentos oriundos da agricultura familiar para serem fornecidos na merenda escolar. Mais especificamente, $30 \%$ (cerca de $\mathrm{R} \$ 1,05$ bilhão) dos recursos provenientes do FNDE para o Programa, devem ser investidos na compra direta de produtos da agricultura, medida que estimula o desenvolvimento econômico e sustentável das comunidades. A nova Lei une o objetivo de melhorar a segurança alimentar e nutricional de estudantes das escolas públicas ao objetivo de disponibilizar uma demanda periódica de alimentos aos agricultores familiares (EMATER, 2013a; MDA, 2015b; SOARES et al, 2013; FNDE, 2015; CONSEA, 2009).

Econ. e Desenv., Santa Maria, vol. 27, n.2, p. 243 - 256, jul. - dez. 2015 RE\&D 
Por fim, ressalta-se que a união dos dois programas é um caminho promissor para melhorar não só as condições de subsistência dos agricultores familiares, mas também para sustentar a segurança alimentar e nutricional em todo o País, é o caso do município de Toledo que uniu não só essas duas políticas públicas, como várias outras em seu favor e está colhendo muitos resultados positivos.

3 Histórico dos restaurantes populares no Brasil

Os restaurantes populares atuais tiveram a sua origem na União Soviética (Costa, 1947). No Brasil, os primeiros restaurantes populares surgiram na década de 1940, com a criação do Serviço de Alimentação da Previdência Social (SAPS) pelo Decreto-Lei n 2.478 de 5 de agosto de 1940, idealizado e elaborado pelo pernambucano Josué de Castro, autor de Geografia da Fome, ganhador do Prêmio Internacional da Paz (MDS, 2010). O programa foi criado com o objetivo principal de proporcionar aos trabalhadores alimentação adequada de baixo custo, promover educação nutricional, formar pessoal técnico especializado e apoiar pesquisas sobre alimentação e nutrição da população. Com o fundador do SAPS a fome no Brasil tornou-se um problema social e tema de debates em nível mundial, trazendo a responsabilidade para os governos e homens (MDS, 2010). No período de sua existência - 1940 a 1967 o SAPS foi responsável por diversas ações de âmbito nutricional, promovendo a instalação dos restaurantes populares no Rio de Janeiro, São Paulo e outras cidades, com o objetivo de proporcionar aos trabalhadores das cidades uma alimentação equilibrada e de preço baixo (VASCONCELOS, 2005).

O termo segurança alimentar só começou a ser disseminado no Brasil na década de 90. Segundo o Frei Betto, um dos mentores das políticas públicas do governo de Lula, essa disseminação ganha força em 16 de outubro de 1991, quando em conjunto com o Instituto da Cidadania, Luís Inácio Lula da Silva lançou oficialmente o programa de segurança alimentar e nutricional, que deu origem ao Programa Fome Zero (MDS, 2010; 2015).

No período entre 1990 e 1999, 8,2 milhões de pessoas haviam saído da condição de indigentes no País e 10,1 milhões haviam saído da condição de pobreza. Essa década mostrou que a melhoria os programas de alimentação e nutrição necessita ser feito em conjunto das diversas políticas públicas. Em 26 de dezembro de 2000, foi criado pelo Governo do Estado de São Paulo, Mário Covas, em parceria com a Secretaria de Agricultura e Abastecimento, o Programa "Restaurantes Populares" chamado Bom Prato. Foi um projeto realizado pelo Programa Estadual de Alimentação e Nutrição para populações carentes, visando oferecer segurança alimentar a população de baixa renda, fornecendo em sua rede de restaurantes populares, refeições balanceadas com qualidade com um cardápio variado (GOBATO et al, 2010).

Para Vasconcelos (2005), no Brasil os restaurantes populares são uma experiência vitoriosa, sendo o programa um meio para solucionar o problema da sub-alimentação da população mais vulnerável. Prova disso são os dados do MDS (2015a), aonde relata que o País conta atualmente com 89 Restaurantes Populares em funcionamento, instalados em 73 municípios, servindo cerca de 123 mil refeições por dia. Em torno de 390 mil pessoas são beneficiadas anualmente com as refeições dos restaurantes populares, geralmente são pessoas com renda que varia entre 1 e 2 salários mínimos, $65 \%$ são do sexo masculino e $40 \%$ possuem ensino médio.

Em 2015, no Estado do Paraná são 14 restaurantes populares instalados em 7 municípios, são eles: Londrina (1), Cascavel (1), Toledo (5), Curitiba (4), Ponta Grossa (1), Paranaguá (1), Maringá (1) e Guarapuava (1), porém apenas as cidades com mais de 100 mil habitantes podem ser beneficiadas com o programa. Toledo é o município que possui mais unidades em todo o Estado, e é o

RE\&D Econ. e Desenv., Santa Maria, vol. 27, n.2, p. 243 - 256, jul. - dez. 2015 
que mais se destaca pelo sucesso do projeto, sendo escolhido como objeto deste estudo. Posteriormente será detalhado o funcionamento destes restaurantes no município.

\subsection{Restaurantes populares de Toledo - Paraná}

Segundo o prefeito da época da instalação do primeiro restaurante popular, José Carlos Schiavinato, o município de Toledo tinha dois desafios de desenvolvimento, um no âmbito da agricultura familiar e da segurança alimentar e nutricional. O primeiro deles era fortalecer a agricultura familiar e o segundo desafio era melhorar a qualidade da alimentação de quem mais precisa no município. A ideia do projeto de construção dos restaurantes populares surgiu quando foram verificados locais de vulnerabilidade social em diversos bairros do município, onde existem trabalhadores em que a empresa não fornece a refeição, crianças em idade escolar, idosos e pessoas de baixa renda. Dentro desta perspectiva, o restaurante Prato Cheio Coopagro foi o primeiro restaurante popular do município de Toledo, situado no bairro Jardim Coopagro e inaugurado em 2006 juntamente com a Cozinha Social (Unidade Central de Produção de Alimentos de Toledo) (SCHIAVINATO, 2015).

O restaurante Prato Cheio Coopagro atendia no início do programa em torno de 500 refeições diárias, em 2010 cada restaurante fornecia em média 400 refeições diárias. Hoje o município possui cinco restaurantes com capacidade de cerca de 3 mil refeições por dia. Em entrevista ao Portal da Cidade de Toledo, o diretor da Cozinha Social, Luiz Bazei, relata que foram feitas melhorias na Cozinha Social em 2014. Essas melhorias têm por objetivo a instalação da usina de soja, visando um melhor aproveitamento da matéria prima do produto, e uma despolpadeira de peixes, aumentando o uso do pescado na merenda escolar e nos restaurantes populares (BAZEI, 2015; JORNAL DO OESTE, 2015).

Nos restaurantes populares diariamente cerca de 1.880 pessoas possuem acesso a uma refeição balanceada preparada com orientação de nutricionistas. Segundo a Prefeitura Municipal em 2006 eram 15 funcionários e hoje são quase 100, divididos entre funcionários municipais e terceirizados. De acordo com a publicação do Jornal do Oeste, o preço da refeição em 2015 subiu $25 \%$, aumentou de $\mathrm{R} \$ 2,00$ para $\mathrm{R} \$ 2,50$, a justificativa para o fato segundo o secretário de administração Amauri Linke é o aumento do preço de custo dos alimentos. Atualmente o custo de cada refeição é de $\mathrm{R} \$ 6,52$, o município custeia mais de $\mathrm{R} \$ 2,50$ por refeição e o Governo Federal custeia em torno de R\$ 1,50 (PREFEITURA MUNICIPAL DE TOLEDO, 2015; BAZEI, 2014; JORNAL DO OESTE, 2015).

Os restaurantes populares de Toledo estão localizados nos seguintes bairros: Coopagro inaugurado em 2006, Boa Esperança e Jardim Europa inaugurado em 2007, São Francisco inaugurado em 2008 e Vila Paulista inaugurado em 2011. Eles são geridos pela Prefeitura Municipal, sendo esse um dos fatores de sucesso do programa, segundo o ex-prefeito da cidade (BAZEI, 2014; SCHIAVINATO, 2015).

O PAA é a política pública utilizada como instrumento para alcançar os objetivos que o município tinha no início do projeto, citados anteriormente pelo ex-prefeito Schiavinato. Por meio deste programa os produtos são adquiridos diretamente dos agricultores familiares ou de suas organizações locais, sem a necessidade de licitação, incentivando os processos de agregação de valor à produção familiar e contribuindo para o fortalecimento da agricultura na região, além de proporcionar alimentação de qualidade e de baixo custo para a população mais necessitada (MDA, 2015; BAZEI, 2014).

Algumas melhorias foram observadas com a implantação do programa no município, o investimento na agricultura foi incentivado, a permanência das pessoas no campo foi garantida,

Econ. e Desenv., Santa Maria, vol. 27, n.2, p. 243 - 256, jul. - dez. 2015 RE\&D 
geraram-se mais empregos, a renda dos produtores familiares aumentou, melhorou a qualidade da alimentação da população com a variedade dos alimentos, melhorou a alimentação dos idosos que preparavam alimentos em casa e não se alimentavam de forma adequada, houve economia também para os cofres públicos evitando desperdícios de alimentos, diminuiram os atendimentos nos postos de saúde, devido a uma alimentação saudável e ainda houve diversificação da economia e o seu fortalecimento, percebeu-se também uma mudança no hábito alimentar, aumento do consumo de verduras, legumes, diminuição da carne e a maior conquista é a consciência de educação alimentar e nutricional por parte dos usuários, essas melhorias contribuíram para que o município ganhasse o prêmio Josué de Castro, como o melhor programa de nutrição do Brasil. Toledo tornou-se ainda um modelo para todo o País e para países vizinhos como Paraguai e Argentina que vieram ver como funciona o programa para implantarem em seus países (SCHIAVINATO, 2015).

A seguir será abordado o tema agricultura familiar, pois sem a interação dos agricultores familiares com a política pública dos restaurantes populares, não é possível obter os resultados positivos do programa.

\section{Agricultura Familiar}

A agricultura é um instrumento singular para o desenvolvimento de uma região e em conjunto com outros setores e políticas públicas pode produzir um crescimento mais rápido, reduzir a pobreza e sustentar o meio ambiente. Sabe-se que a expressão agricultura familiar emergiu no contexto brasileiro a partir de meados da década de 1990, relacionada com os movimentos sindicais. Sua consagração aconteceu com a institucionalização de agricultores familiares a partir da consolidação do PRONAF e depois do projeto Fome Zero, momento em que a agricultura familiar passou ser vista como estratégia, frete ao seu papel no fornecimento interno de alimentos e a sua capacidade de resposta, mesmo com crises globais de alimentos (STOFELL, 2004; SCHNEIDER, 2009; PLANSAN, 2011).

Para STOFELL (2013), a agricultura familiar é importante para o desenvolvimento do País. Autores como Guilhoto acreditam que a agricultura familiar é importante para a economia brasileira devido a fatores, como: geração de emprego e renda, redução das pressões sociais sobre as cidades e da destinação de seus produtos ao mercado interno (GUILHOTO et al 2005). Já a Organização das Nações Unidas para Alimentação e Agricultura (FAO) afirma que quando trabalhada em conjunto com políticas específicas destinadas a promover a proteção social e o bem-estar dos municípios, a agricultura familiar é uma oportunidade para dinamizar as economias locais e aumentar o nível de segurança alimentar (FAO, 2015).

Para o Governo Federal, a agricultura familiar tem semeado profissionalismo, cultivado tecnologias e políticas públicas, colhido oportunidades e comercializado saúde no País. Pesquisas mostram que em 2014 ela representou 33\% do PIB agropecuário do País, nesse mesmo ano o segmento representou cerca de 12 milhões de pessoas no País, ocupando $74 \%$ da mão de obra no campo, tornando-se a responsável por $70 \%$ dos alimentos consumidos pelos brasileiros, superando o estigma de agricultura de subsistência (PORTAL BRASIL, 2014).

Neste contexto torna-se imprescindível a necessidade de se implantar projetos de desenvolvimento voltados aos agricultores familiares, já que muitas localidades apresentam condições para dinamizarem suas atividades econômicas e, consequentemente, elevarem sua renda e bem estar. Os agricultores familiares são agentes inseridos no sistema econômico capitalista, cuja satisfação depende do acesso aos recursos para atender as necessidades, como: ter acesso à saúde, educação, habitação de qualidade e opções de lazer, são fatores que estimulam a permanência do homem no campo. A busca por diversificação da produção para obter maior renda também auxilia nesse processo

RE\&D Econ. e Desenv., Santa Maria, vol. 27, n.2, p. 243 - 256, jul. - dez. 2015 
e é fundamental para conseguir maiores níveis de desenvolvimento rural. Para isso é necessário que os agricultores atuem em atividades produtivas que contribuam para o alcance dessas condições de vida (STOFELL, 2004; CAUMO; STADUTO, 2014; STOFELL, 2013).

O responsável pelo recebimento dos produtos na Cozinha Social, Senhor Moacir Pereira dos Santos, comenta em 2014, o Programa de Aquisição de Alimentos (PAA), beneficiou 219 agricultores famílias locais, para o ex-prefeito do município, com o programa Toledo conseguiu melhorar a qualidade de vida do homem do campo, melhorar o associativismo e ainda fortaleceu a feira local, onde $50 \%$ dos produtores que expõem seus produtos na feira tiveram início nesses programas. Toda produção é entregue diariamente para a Cozinha Social, ali os alimentos são processados e posteriormente, são entregues às entidades do município (restaurantes populares, escolas, hospitais, creches entre outras) sendo a cozinha uma centralizadora do processo, outro diferencial do projeto. Os produtos entregues são todos os tipos de hortaliças, e em sua maioria são produtos não orgânicos. Os produtores que produzem os produtos de forma orgânica recebem uma bonificação, ou seja, um valor diferenciado pelo seu produto, porém, esse produtor precisa ser certificado pela secretaria da agricultura do município para fazer a comercialização do produto. Para o Senhor Moacir, esses produtores tem visto no PAA uma possibilidade de organizar e planejar parte da produção, que não eram prioridade na propriedade, assim eles precisam ter uma estratégia com relação ao processo produtivo, uma vez que o fornecimento dos produtos é periódico. Em se tratando dos benefícios da participação no programa, ele acredita que os produtores rurais além de venderem seus produtos com preços tabelados (às vezes melhores que os de mercado), eles possuem a garantia de que todos os produtos e toda sua produção serão comercializados, outra vantagem é em relação ao pagamento, que é realizado assim que a nota fiscal de produtor rural é apresentada na Prefeitura (SANTOS, 2015; SCHIAVINATO, 2015).

Todos os produtores rurais de Toledo aderiram ao programa PRONAF e assim conseguem crédito rural com juros baixos para incentivar o investimento na produção agrícola. Políticas públicas como o PRONAF têm contribuído com a agricultura familiar, a parceira entre os agricultores e o programa favorece a geração de renda e melhora as condições da qualidade de vida no campo, além de auxiliar na diversificação da produção, abrir novos mercados, valorizar os produtos locais e fortalecer as organizações sociais (SANTOS, 2015; GUANZIROLI, 2007).

\section{CONCLUSÃO}

Conclui-se que talvez o maior desafio que se apresenta hoje para minimizar ou solucionar os problemas sociais que reside no País é pensar em políticas públicas que não ataquem apenas o efeito do problema e sim a sua causa, fazendo com que o resultado dessa ação seja multiplicador em todos os âmbitos. Os restaurantes populares de Toledo conseguiram avanços significativos em seus quase nove anos de existência, as melhorias contribuíram inclusive para que o município ganhasse o prêmio Josué de Castro, como o melhor programa de nutrição do Brasil. Sua parceria com outras políticas públicas teve papel primordial para promover o desenvolvimento da região, transformando a realidade da população mais vulnerável, beneficiando as pessoas que vivem no meio rural, fortalecendo a indústria, gerando emprego e dinamizando a economia local.

Por fim, ressalta a importância de políticas públicas bem geridas pela gestão pública, trabalhadas de forma a muderem o foco de políticas públicas para atender os problemas das necessidades básicas para o da cidadania.

Econ. e Desenv., Santa Maria, vol. 27, n.2, p. 243 - 256, jul. - dez. 2015 RE\&D 


\section{REFERÊNCIAS}

ARAUJO; SILVA et al. O Programa de Aquisição de Alimentos como instrumento de efetivação do Direito Humano à Alimentação Adequada: uma análise da modalidade Compra com Doação Simultânea operacionalizada pela Conab em 2013. 2013. Disponível em:<http://www.conab.gov.br/OlalaCMS/uploads/arquivos/14_09_15_16_06_44_dhaa_e_san_artigo_ sober_2014_arquivo_2.pdf. Acesso em: 01 fev. 2015.

BARROS, R. et al. Desigualdade de renda no Brasil: uma análise da queda recente. V. 02. 552 p. Brasília: IPEA, 2007.

BNDES - Banco Nacional do desenvolvimento. Programa Nacional de Fortalecimento da Agricultura Familiar - Pronaf Investimento. 2015. Disponível em:<http://www.bndes.gov.br/apoio/pronaf.html>. Acesso em: 02 fev. 2015.

BAZEI, L. Entrevista concedida a Elaine Zanini. Toledo, 15 dez. 2014.

BAZEI, L. Restaurantes Populares de Toledo voltam a atender. 2015. Disponível em:<http://toledo.portaldacidade.com/noticia/id/2005/>. Acesso em: 18 jun. 2015.

CAUMO, A.J; STADUTO, J.A.R. Produção Orgânica: uma alternativa na agricultura familiar. Revista Capital Científico, v. 12, n. 2, abr/jun 2014.

CONSEA - Conselho Nacional de Segurança Alimentar e Nutricional. Construção do Sistema e da Política Nacional de Segurança Alimentar e Nutricional: a experiência brasileira. Brasília. 2009.

COSTA D. Experiência Brasileira em Restaurantes Populares. 1947. Disponível em:<http://hist.library.paho.org/Spanish/BOL/v26n5p415.pdf>. Acesso em: 07 jan. 2015.

CRUZ, K. C. M. S. dos. et al. O acesso da agricultura familiar brasileira às políticas públicas: a evolução do programa de aquisição de alimentos. 2014. Disponível em:<http://www.conab.gov.br/OlalaCMS/uploads/arquivos/14_09_15_16_03_05_artigo_evolucao_do _paa_2.pdf>. Acesso em: 01 fev. 2015.

EMATER - Instituto Paraense de Assistência Técnica e Extensão Rural. Projeto Crédito Rural. 2013. Disponível em:<http://www.emater.pr.gov.br/modules/conteudo/conteudo.php?conteudo=97>. Acesso em: 18 fev. 2015.

EMATER - Instituto Paraense de Assistência Técnica e Extensão Rural. Secretaria de Estado da agricultura e do abastecimento conselho estadual de desenvolvimento rural e agricultura familiar - CEDRAF. 2013a. Disponível em:<

http://www.emater.pr.gov.br/arquivos/File/Programas_de_Governo/Cedraf/Atas/ATA_058.pdf〉. Acesso em: 18 fev. 2015.

FAO - Organização das Nações Unidas para Alimentação e Agricultura. Por que a agricultura familiar é importante? 2015. Disponível em:<http://www.fao.org/family-farming-2014/pt/>. Acesso em 01 jun 2015.

RE\&D Econ. e Desenv., Santa Maria, vol. 27, n.2, p. 243 - 256, jul. - dez. 2015 
FNDE - Fundo Nacional de Desenvolvimento da Educação. 2015. Alimentação Escolar (PNAE) Apresentação. Disponível em:<http://www.fnde.gov.br/index.php/programas/alimentacaoescolar/alimentacao-escolar-apresentacao>. Acesso em: 20 de maio de 2015.

GUANZIROLI, C. E. PRONAF dez anos depois: resultados e perspectivas para o desenvolvimento rural. Revista de Economia e Sociologia Rural, vol. 45, n.02, Brasília, abr/jun, 2007.

GUILHOTO, J. J. et al. Agricultura familiar na economia: Brasil e Rio Grande do Sul. Estudos NEAD 9. Brasília: MDA, 2005.

JORNAL DO OESTE. Sem aviso, reajuste de $25 \%$ na refeição pegou a população de surpresa. 2015. Disponível em:<http://www.jornaldooeste.com.br/cidade/2015/02/sem-aviso-reajuste-de-25-narefeicao-pegou-populacao-de-surpresa/1270468/>. Acesso em 01 mar. 2015.

MERIGO, J; ANDRADE. M. M. de. Questões iniciais para a discussão do monitoramento e avaliação de políticas públicas. 2010.

MDA - Ministérios do Desenvolvimento Agrário. Ministro do Desenvolvimento Agrário destaca importância das políticas públicas. 2013. Disponível em:<

http://www.mda.gov.br/sitemda/noticias/ministro-destaca-import\%C3\%A2ncia-das-prefeituras-paraamplia\%C3\%A7\%C3\%A3o-das-pol\%C3\%ADticas-p\%C3\%BAblicas >. Acesso em: 25 fev. 2015.

MDA - Ministério do Desenvolvimento Agrário. PAA. 2015a. Disponível em:

<http://www.mda.gov.br/sitemda/secretaria/saf-paa/sobre-o-programa. Acesso em: 01 fev. 2015.

MDA - Ministério do Desenvolvimento Agrário. Agricultores familiares do Paraná atenderão 97\% dos municípios do estado. 2015b. Disponível em:

$<$ http://www.mda.gov.br/sitemda/noticias/agricultores-familiares-do-paran\%C3\%A1-

atender\%C3\%A3o-97-dos-munic\%C3\%ADpios-do-estado\#sthash.8tJLDHnN.dpuf>. Acesso em: 19 maio 2015 .

MDS - Ministério do Desenvolvimento Social e Combate à Fome. Fome Zero: Uma História Brasileira. 2010. Disponível

em:<http://www.mds.gov.br/saladeimprensa/noticias/2011/agosto/Fome,P20Zero,P20Vol1.pdf.pagesp eed.ce.qqzWYtqMJC.pdf>. Acesso em: 16 fev. 2015.

MDS - Ministério do Desenvolvimento Social e Combate à Fome. Restaurantes Populares. 2015. Disponível em:〈http://www.mds.gov.br/segurancaalimentar/equipamentos/restaurantespopulares〉. Acesso em: 16 fev. 2015.

MDS - Ministério do Desenvolvimento Social e Combate à Fome. Modalidades. 2015a. Disponível em:<http://www.mds.gov.br/segurancaalimentar/aquisicao-e-comercializacao-da-agriculturafamiliar/entenda-o-paa/modalidades-1>. Acesso em: 02 fev. 2015.

MDS - Ministério do Desenvolvimento Social e Combate à Fome. Assistência Técnica e Extensão Rural. 2015b.Disponível em: <http://www.mds.gov.br/falemds/perguntas-frequentes/superacao-daextrema-pobreza\%20/inclusao-produtiva-rural/assistencia-tecnica-e-extensao-rural<. Acesso em: 10 mar. 2015.

Econ. e Desenv., Santa Maria, vol. 27, n.2, p. 243 - 256, jul. - dez. 2015 RE\&D 
MDS - Ministério do Desenvolvimento Social e Combate à Fome. Redes de equipamentos. 2015c. Disponível em:< http://www.mds.gov.br/segurancaalimentar/equipamentos >. Acesso em 15 abr. 2015.

PREFEITURA MUNICIPAL DE TOLEDO. Restaurantes Populares. 2015. Disponível em:<http://www.toledo.pr.gov.br/portal/restaurantes-populares/restaurantes-populares >. Acesso em 01 mar. 2015.

PORTAL BRASIL. Agricultura familiar encerra 2013 com recordes e traça metas. 2014. Disponível em: <http://www.brasil.gov.br/economia-e-emprego/2014/01/agricultura-familiar-encerra2013-com-recordes-e-traca-metas>. Acesso em: 19 maio 2015.

PLANSAN - Plano Nacional de Segurança Alimentar e Nutricional 2012 -2015. Brasília. 2011.

PLANSAN - Plano Nacional de Segurança Alimentar e Nutricional. Balanço das Ações do Plano Nacional de Segurança Alimentar e Nutricional 2012 - 2015. Brasília. 2014.

SANTOS, M. de. P. Entrevista concedida a Elaine Zanini. Toledo, 18 mar. 2015.

SCHNEIDER, S. A pluriatividade na agricultura familiar. 2. ed. Porto Alegre: Editora da UFRGS, 2009.

SCHIAVINATO, J.C. Entrevista concedida a Mirian Schneider. Toledo, 10 jan. 2015.

SOARES, F. V. et al (Coord). Demanda Estruturada e a Agricultura Familiar no Brasil: o Caso do PAA e do PNAE. Brasília, 2013.

STOFELL. J.A. A viabilidade da agricultura familiar: Formas de organização produtiva no Oeste do Paraná. 2004. 128f. Programa de Pós-Graduação em Desenvolvimento Regional e AgronegócioMestrado e Doutorado. Toledo. Dissertação (Mestrado em Desenvolvimento Regional e Agronegócio) - PGDRA - UNIOESTE.

STOFELL, J. Influência da agricultura familiar no desenvolvimento rural na região Sul do Brasil. 2013. 291f. Programa de Pós-Graduação em Desenvolvimento Regional - Mestrado e Doutorado. Santa Cruz do Sul. Tese (Doutorado Desenvolvimento Regional) - UNISC.

VASCONCELOS, F. A. G. Combate à fome no Brasil: uma análise histórica de Vargas a Lula. Revista de Nutrição, Campinas, v. 18, n. 4, p. 439-457, ago. 2005.

RE\&D Econ. e Desenv., Santa Maria, vol. 27, n.2, p. 243 - 256, jul. - dez. 2015 